\title{
Stenting or balloon angioplasty of stenosed autologous saphenous vein grafts in pigs
}

\begin{abstract}
In a model of early and aggressive vein graft stenosis in pigs, an intervention was performed with a single stent ( $n=12$ grafts), multiple stents $(n=6)$, or balloon angioplasty $(n=6)$, while grafts with mild stenoses were left untreated $(n=8)$. Four weeks after intervention, angiography showed that grafts with single stents, balloon angioplasty, or untreated grafts had patency rates of $92 \%, 83 \%$, and $83 \%$, respectively. Grafts receiving multiple stents, however, showed only a $17 \%$ patency rate $(p<0.05)$. Balloon dilatation or placement of a single stent improved the angiographic minimal diameter by $0.6 \pm 0.2$ and $0.8 \pm 0.3 \mathrm{~mm}$, respectively, over the short term, but this gain was lost during the follow-up period. Multiple stents showed a similar gain $(0.5 \pm 0.2 \mathrm{~mm})$ but more loss occurred during the follow-up period $(2.4 \pm 0.2 \mathrm{~mm})$. Histology revealed no significant differences between the treatment groups except for the prolonged presence of thrombus remnants in association with the stent wires. In conclusion, single stents and balloon angioplasty show good patency in early saphenous vein graft narrowing but multiple stents show a high occlusion rate. (AM HEART J 1994;127:273-81.)
\end{abstract}

Heleen M. M. van Beusekom, MSc, Patrick W. Serruys, MD, Johannes C. Post, MD, Pieter D. Verdouw, $\mathrm{PhD}$, and Willem J. van der Giessen, MD

Rotterdam, The Netherlands

Coronary artery bypass graft (CABG) operations using autologous saphenous veins are a widely employed surgical therapy for obstructive atherosclerotic coronary artery disease. Up to $12 \%$ of grafts, however, occlude within 1 month after the operation, with an additional $10 \%$ occlusion rate during the first year. A subsequent yearly occlusion rate of $2 \%$ has been reported, resulting in a $65 \%$ patency rate at 5 years. ${ }^{1,2}$ Repeat bypass surgery is feasible in most cases, but is associated with an increased morbidity and mortality, while long-term patency is inferior to that of the first procedure. ${ }^{3-5}$ Moreover, a significant number of patients for several reasons are poor candidates for repeat surgery. ${ }^{6}$ Percutaneous transluminal coronary angioplasty (PTCA) may be an alternative to surgery in these patients. The initial success rate of this procedure is high $(90 \%)$, but the restenosis rate after P'CA in bypass graft is considerable, and only $41 \%$ of patients are alive and event-free af-

From the Department of Cardiology, Thoraxcenter, Erasmus University Rotterdam.

Supported by Medtronic Inc., Minneapolis, Minn.

Received for publication April 26, 1993; accepted June 7, 1993.

Reprint requests: Heleen MM van Beusekom, MSc, Department of Cardiology, Thoraxcenter, Ee 2357, Erasmus University Rotterdam, PO Box 1738, 3000 DR Rotterdam, The Netherlands.

Copyright 1994 by Mosby-Year Book, Inc.

$0002-8703 / 94 / \$ 1.00+.10 \quad \mathbf{4} / 1 / 51125$ ter 2 years. ${ }^{7}$ Additionally, not all patients are candidates for balloon angioplasty. ${ }^{6}$

The implantation of endovascular prostheses, also called stents, seems a promising new technique for treatment and prevention of restenosis in these patients. ${ }^{8,9}$ The angiographic and histologic results after stent implantation in bypass grafts have only been reported to a limited extent. ${ }^{9-12}$ We therefore studied the placement of stents in an animal model for autologous saphenous vein grafting ${ }^{13}$ and compared the results with those of balloon angioplasty alone, or with those following no intervention at all.

\section{METHODS}

Vein graft model. Experiments were performed in 31 Yorkshire pigs (17 to $30 \mathrm{~kg}$; HVC, Hedel, The Netherlands). The protocol was approved by the Committee on Experimental Animals of Erasmus University. After an overnight fast the animals were sedated with $20 \mathrm{mg} / \mathrm{kg}$ ketamine hydrochloride (Ketalin; Apharmo BV, Arnhem, The Netherlands). Following endotracheal intubation, the pigs were connected to a ventilator that administered a mixture of oxygen and nitrous oxide $(1: 2, \mathrm{vol} / \mathrm{vol})$. Anesthesia was maintained with 1 to $4 \mathrm{vol} \%$ enflurane (Ethrane; Abbot BV, Maalderij, The Netherlands). Antibiotic prophylaxis was administered by an intramuscular injection of $1000 \mathrm{mg}$ of a mixture of penicillin $\mathrm{G}$ procaine and penicillin G benzathine (Duplocillin; Gist-Brocades NV, Delft, The Netherlands).

The implantation of two venous grafts was performed 


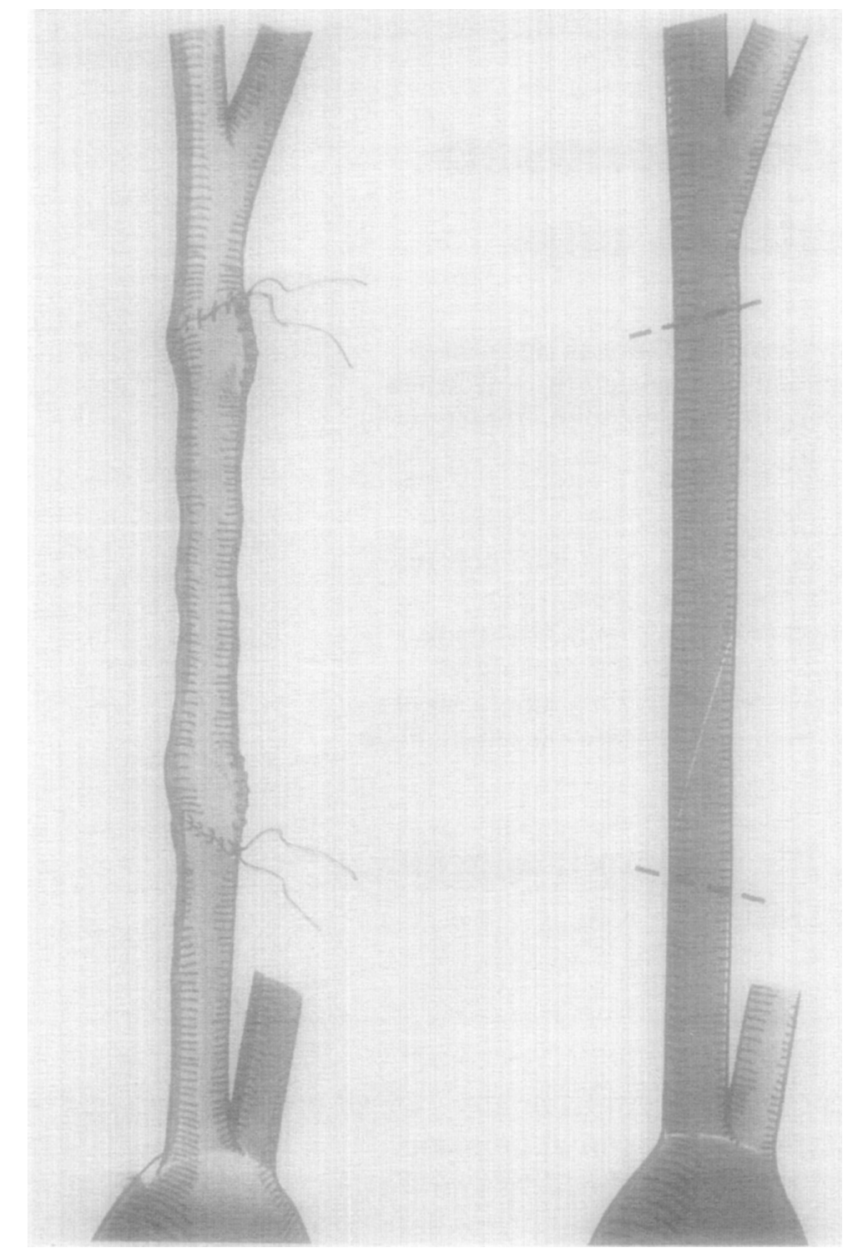

Fig. 1. Schematic representation of the vein graft model showing how the vein is interposed in the carotid artery. (Courtesy of Professor G. D. Angelini, Bristol, England.)

according to the methods described by Angelini et al. ${ }^{13}$ (Fig. 1). Briefly, skin incisions were made parallel to and approximately $3 \mathrm{~cm}$ lateral to the trachea on both sides. Both common carotid arteries were dissected free over a length of approximately $4 \mathrm{~cm}$ and were subsequently covered with gauze soaked in a $1 \%$ papaverine solution $(\mathrm{Pa}-$ parini sulfas; Centrafarm BV, Etten-leur, The Netherlands) to prevent vasospasm. The vena saphena minor of the left leg was prepared free over a distance of approximately $5 \mathrm{~cm}$ and the larger side branches were secured. After removal, the vein was overdistended using a syringe containing a solution of $1 \%$ papaverine and $10 \mathrm{U} / \mathrm{ml}$ of heparin (Thromboliquine; Organon Teknika BV, Boxtel, The Netherlands). Thereafter two pieces of vein, approximately $15 \mathrm{~mm}$ in length, were excised and stored in the same solution. After cross clamping of one carotid artery, a $15 \mathrm{~mm}$ piece of the vessel was removed and was replaced by a piece of saphenous vein by two end-to-end anastomoses using a 6.0 suture (Prolene; Ethicon, Norderstedt, Germany). After intravenous administration of $2500 \mathrm{U}$ of heparin, the clamps were released. The contralateral carotid artery was grafted in an identical way. The anasto- motic sites were marked with stainless steel hemoclips. Neck and leg wounds were closed in layers using catgut (Chronic Gut; American Cyanamid Co., Wayne, N.J.) and the skin was covered with antiseptic spray (Nobecutane; Astra Pharmaceutica BV, Rijswijk, The Netherlands). Thereafter the animals were allowed to recover from anesthesia. Two animals died during the first days after surgery.

Follow-up angiography. Four weeks after surgery 29 animals were anesthetized as described above. Under sterile conditions an arteriotomy of a femoral artery was performed and a $9 F$ introduction sheath was inserted. Then $5000 \mathrm{IU}$ of heparin sodium was administered and an $8 \mathrm{~F}$ guiding catheter was advanced to the aortic arch. After measurement of arterial blood pressure and heart rate and withdrawal of an arterial blood sample for the measurement of blood gases and acid-base balance (settings of the ventilator corrected, if necessary), angiography of the grafted carotid arteries was performed using iopanidul (Iopamiro 370; Dagra, Diemen, The Netherlands) as a contrast agent. Only animals with at least one patent graft were used for further study. One animal with two patent grafts was excluded from the study because of infection. In this animal the acute effect of 2 hours of stent placement was studied by scanning electron microscopy.

Balloon-expandable stent. The balloon-expandable stent used in this study (Wiktor, Medtronic Inc., Minneapolis, Minn.) is constructed of a single tantalum wire $(0.127 \mathrm{~mm}$ in diameter $)$ that is formed into a sinusoidal wave and wrapped into a helical coil structure. This prosthesis is crimped onto the deflated polyethylene balloon of a standard angioplasty catheter. The features of this prosthesis design are such that by inflating the balloon the diameter of the stent increases without alteration of its length. ${ }^{14}$ The maximal diameter of the balloon after inflation determines the ultimate size of the prosthesis after implantation. One inflation at $8 \mathrm{~atm}$ is sufficient to open the stent and permit the safe withdrawal of the deflated balloon (Fig. 2). The balloon diameters of the mounted angioplasty catheters used in this study were $4.0 \mathrm{~mm}$, and the lengths of the prostheses were 14 to $16 \mathrm{~mm}$.

Intervention. From the angiograms the patent grafts were divided into four groups by visual assessment (Table I). A first group of eight grafts (12 anastomotic sites) was considered to manifest mild stenoses and an intervention was not performed in these grafts to allow the study of progression of vein graft hyperplasia. A second group of six grafts was dilated by a $4.0 \mathrm{~mm}$ angioplasty balloon up to 8 atm for 40 seconds. A third group of 12 grafts received a single $4.0 \mathrm{~mm}$ stent covering the narrowest arteriovenous anastomosis. A last group of six grafts received two or three stents covering both anastomotic sites and the body of the graft. The implantation procedure of the $4.0 \mathrm{~mm}$ balloonexpandable stents was similar to the procedures described earlier for the coronary circulation. ${ }^{14}$ After stent implantation and balloon dilatation repeat angingraphy was performed, the guiding catheter and the introducer sheath were removed, the arteriotomy was repaired, and the skin was closed in two layers. The animals were allowed to recover from anesthesia. After the procedure, antithrombotic 


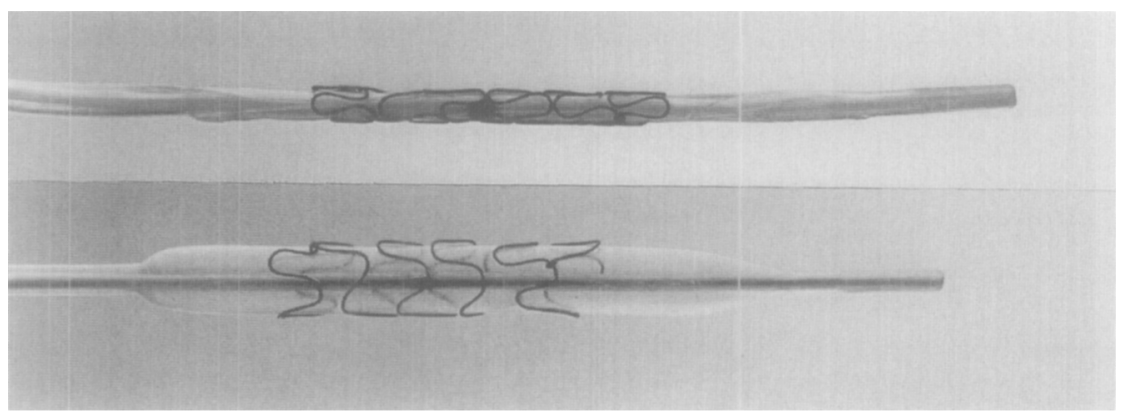

Fig. 2. The Wiktor stent mounted on the balloon before inflation (top) and after inflation of the balloon (bottom).

drugs were not administered at any time during the follow-up period.

Follow-up angiography and harvesting of the specimen. Follow-up angiography was performed after 31 days using the samc projection and identical geometry of the $\mathrm{x}$-ray gantry as used during implantation. Thereafter the carotid arteries were dissected free. After cross-clamping and puncturing of the proximal part of the arteries, $500 \mathrm{ml}$ of saline followed by $400 \mathrm{ml}$ of buffered $4 \%$ paraformaldehyde was infused under a pressure of approximately 120 $\mathrm{mm} \mathrm{Hg}$. The specimens were placed in $4 \%$ paraformaldehyde for light microscopy, or in $4 \%$ paraformaldehyde plus $1 \%$ glutaraldehyde in phosphate buffer $(\mathrm{pH} 7.3)$ for at least 48 hours in preparation for electron microscopy.

Angiographic analysis. Angiograms (performed immediately before and after intervention and again after 31 days) were analyzed off-line using the quantitative Cardiovascular Measuring System (CMS) software (Medis Medical Imaging Systems, Nuenen, The Netherlands). ${ }^{15}$ The minimal luminal diameter at the site of the intervention was measured, provided that the angiographic view was not obstructed by the hemoclip.

Microscopic analysis. After fixation, the graft-containing arterial segments were divided lengthwise into two equal parts using a pair of fine scissors. One part was washed in $0.1 \mathrm{~mol} / \mathrm{L}$ cacodylate buffer $(\mathrm{pH} \mathrm{7.3)}$ and was postfixed in $1 \% \mathrm{OsO}_{4}$ in $0.1 \mathrm{~mol} / \mathrm{L}$ cacodylate buffer for at least 6 hours. After it was washed overnight in $0.1 \mathrm{~mol} / \mathrm{L}$ cacodylate buffer, the specimen were placed in $1 \%$ tannic acid for 60 minutes, in $1 \%$ sodium sulfate for 10 minutes, and was again washed in $0.1 \mathrm{~mol} / \mathrm{L}$ cacodylate buffer. After dehydration in a graded ethanol series and an overnight incubation in uranyl acetate/ethanol ( 7 parts ethanol $100 \% ; 3$ parts uranyl acetate saturated in aqua dest), the specimens were critical point dried with liquid $\mathrm{CO}_{2}$, mounted on a specimen table, and sputtercoated with gold before examination in a scanning electron microscope (ISI-DS-130; Akashi Beam Technology, Tokyo, Japan).

For light microscopy and immunocytochemistry, 3 to 4 $\mathrm{mm}$ wide transverse sections of the second part of the vessels were made with a pair of fine scissors and a sharp razor blade. With tweezers and with the aid of a dissection microscope, the metal stent wires were carefully removed and the tissue was dehydrated and embedded in paraffin. After
Table I. Number of animals, grafts, and patency rates per intervention group

\begin{tabular}{lccc}
\hline Intervention group & $\begin{array}{c}\text { Animals } \\
(n)\end{array}$ & $\begin{array}{c}\text { Grafts } \\
(n)\end{array}$ & $\begin{array}{c}\text { Patency } \\
(\%)\end{array}$ \\
\hline No intervention & 7 & 8 & 83 \\
Balloon angioplasty & 6 & 6 & 83 \\
Single stent & 12 & 12 & 92 \\
Multiple stent & 6 & 6 & $17^{*}$ \\
\hline
\end{tabular}

${ }^{*} p<0.05$ versus other treatment groups.

sectioning and staining, microscopy was performed using a light microscope (BH2; Olympus, Tokyo, Japan). Hematoxylin-azophloxin was used as a routine stain, resorcinlfuchsin was used as an elastin stain, and Goldner was used as a trichrome stain.

Immunocytochemistry. After rehydration, the sections were exposed to monoclonal mouse anti-smooth muscle cell-specific $\alpha$-actin (Sigma Chemical Company, St Louis, Mo.), mouse monoclonal anti-porcine vimentin, and mouse anti-porcine desmin (Dakopatts, Glostrup, Denmark) as a marker for smooth muscle cells. As a second antibody, horseradish peroxidase-labeled rabbit anti-mouse antibodies were used (Dakopatts). As a detecting reagent 700 $\mu \mathrm{g} / \mathrm{ml}$ of diaminobenzidine (Sigma Chemical Company) in phosphate-buffered saline was used.

Statistical analysis. All data are expressed as mean \pm SEM, unless otherwise stated. Differences in patency between the intervention groups were analyzed by the chi square test. The significance of the changes in the angiographic data were evaluated by Duncan's new multiple range test once an analysis of variance (ANOVA) had revealed that the samples represented different populations (random block design). A $p$ value less than 0.05 was considered statistically significant.

\section{RESULTS}

Vein graft model. Repeat angiography 31 days after surgery showed that 32 grafts ( 20 animals) out of a total of 58 grafts were angiographically patent $(45 \%$ occlusion rate). All occluded grafts were blocked over their entire length, and were excluded from further study. 


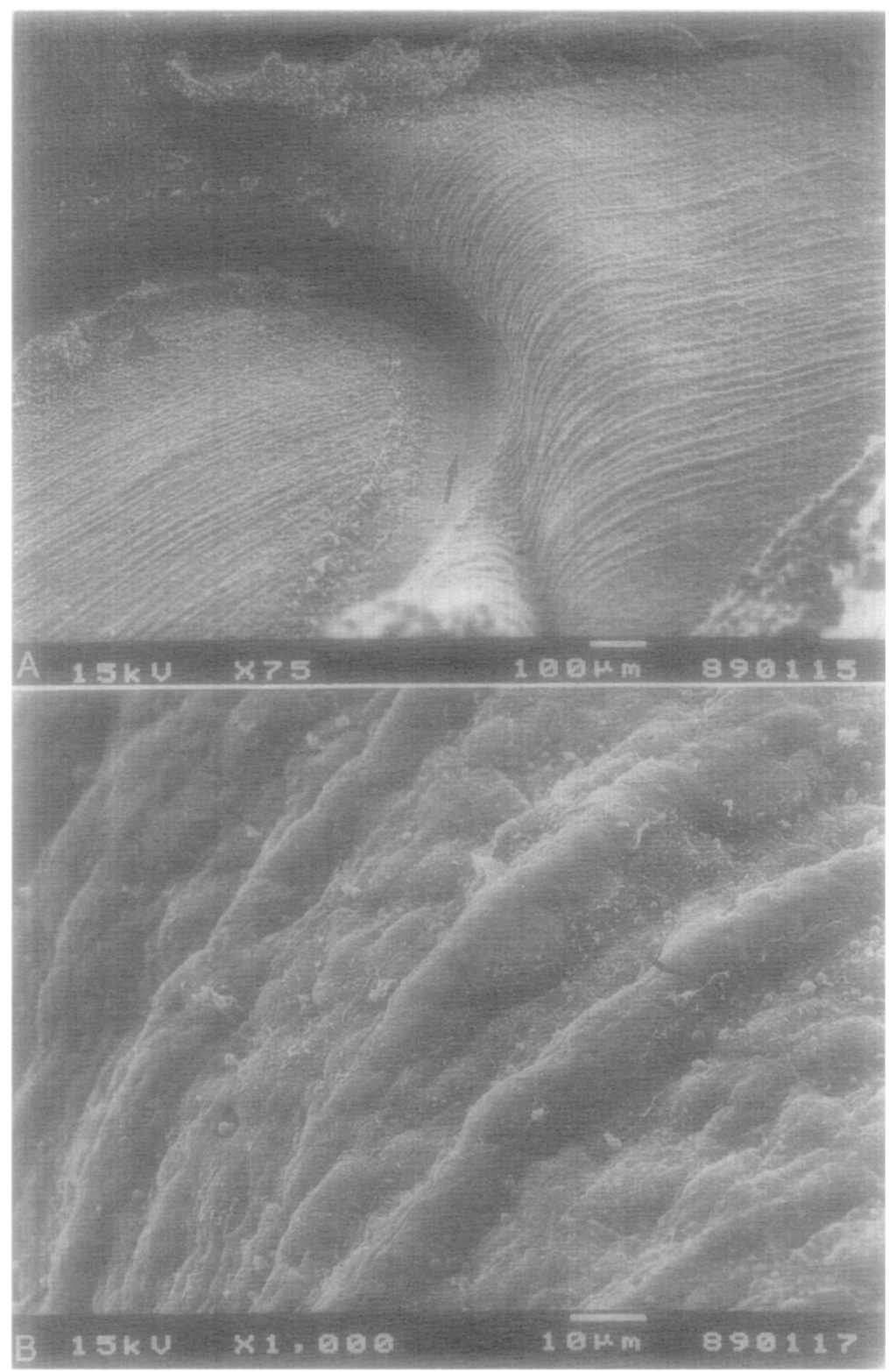

Fig. 3. A, Scanning electron microscopy of a 31 -day-old vein graft 2 hours after implantation of the stent revealed trenches (arrow) where the stent wires were located before preparation for microscopy, with thrombus remnants in close apposition (arrowhead). Damage to the vessel wall seems limited to the trenches created by the stent wires, while the remaining endothelium appears undamaged. B, Detail of $\mathbf{A}$ showing the apparently undamaged endothelium just above the stent wirc.

Hemodynamics during intervention. Immediately before intervention in the grafts, the heart rate was $105 \pm 5$ beats $/ \mathrm{min}$, and systolic and diastolic arterial blood pressure measured $129 \pm 5$ and $93 \pm 5 \mathrm{~mm}$ $\mathrm{Hg}$, respectively.

Acute effect of stenting. The acute effect of stenting was studied by scanning electron microscopy in one animal 4 weeks after surgery at 2 hours after stent placement. The luminal appearance of the vein graft had a waveform geometry after placement of the stent. Because of the open sinusoidal configuration, parts of the vessel wall not covered by the wires were bulging out into the lumen (Fig. 3, A). At a higher magnification an undulating surface was seen that had an undamaged appearance and that was lined by endothelium. Damage to the vessel wall was only observed at the site where previously the stent wires had been present (Fig. 3, B).

Angiographic patency 4 weeks after intervention. Qualitative assessment of the angiograms of the four groups revealed that the patency rates after 4 weeks of follow-up of the groups receiving no intervention, those receiving balloon dilatation, or those with a single stent were $83 \%, 83 \%$, and $92 \%$, respectively 
No intervention
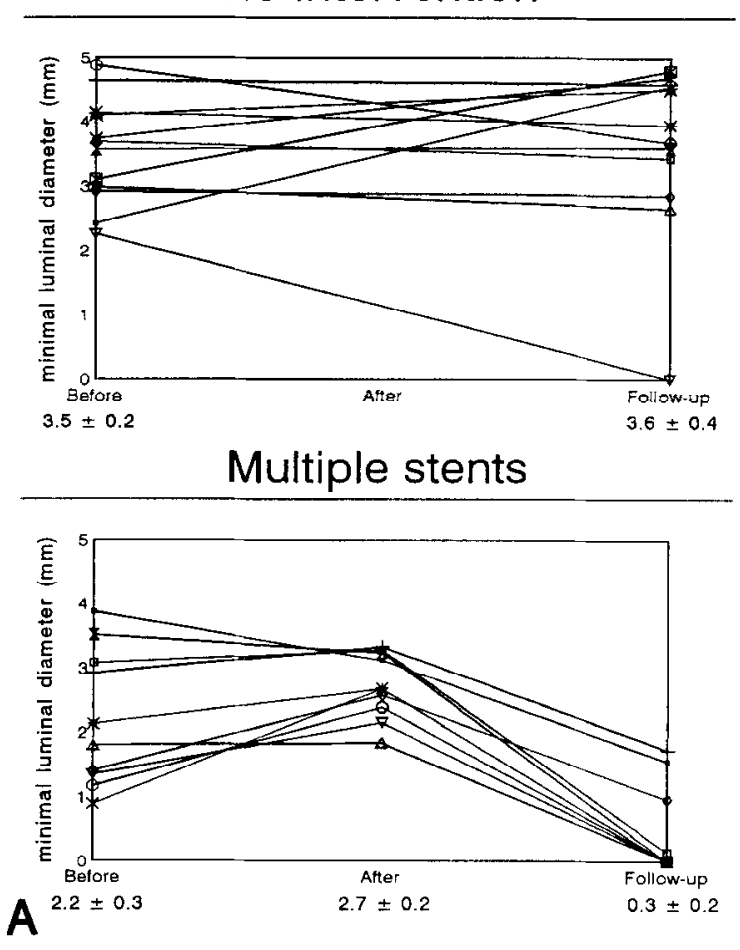

No intervention

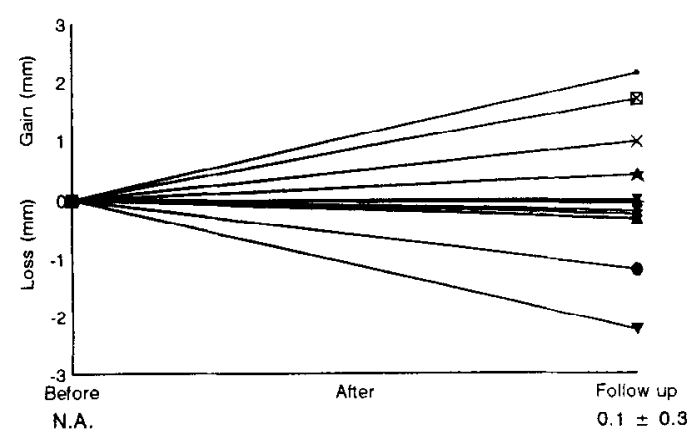

Multiple stents

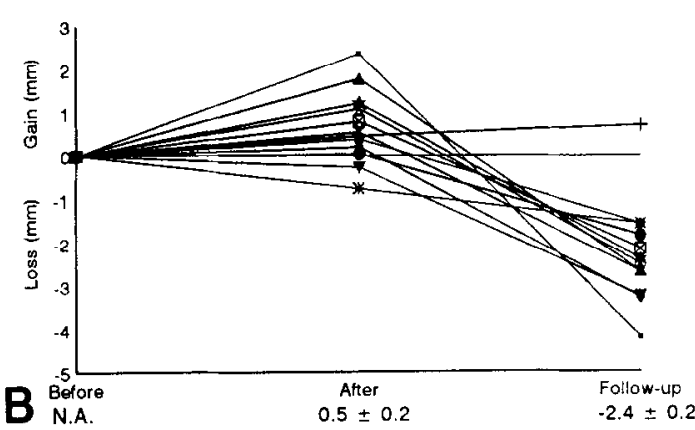

\section{Balloon angioplasty}
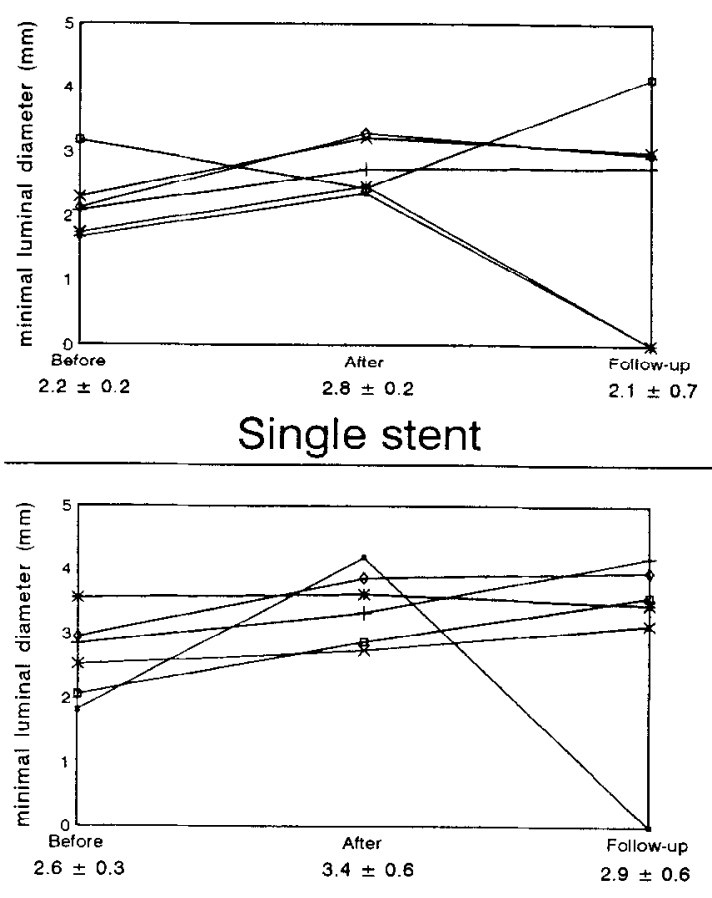

Balloon angioplasty
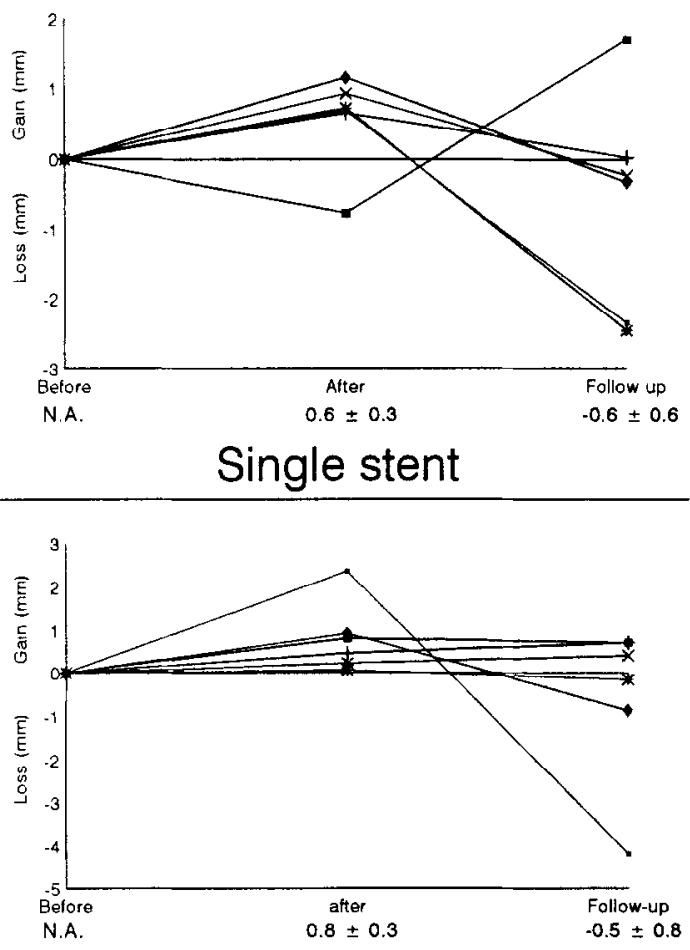

Fig. 4. A, Individual angiographic data and mean minimal luminal diameter ( $\mathrm{mm} \pm \mathrm{SEM}$ ) at the site of intervention before and after intervention and after 4 weeks of follow-up. B, Individual data and mean $( \pm \mathrm{SEM})$ of the loss or gain in minimal luminal diameter after intervention and after 4 weeks of follow-up. 


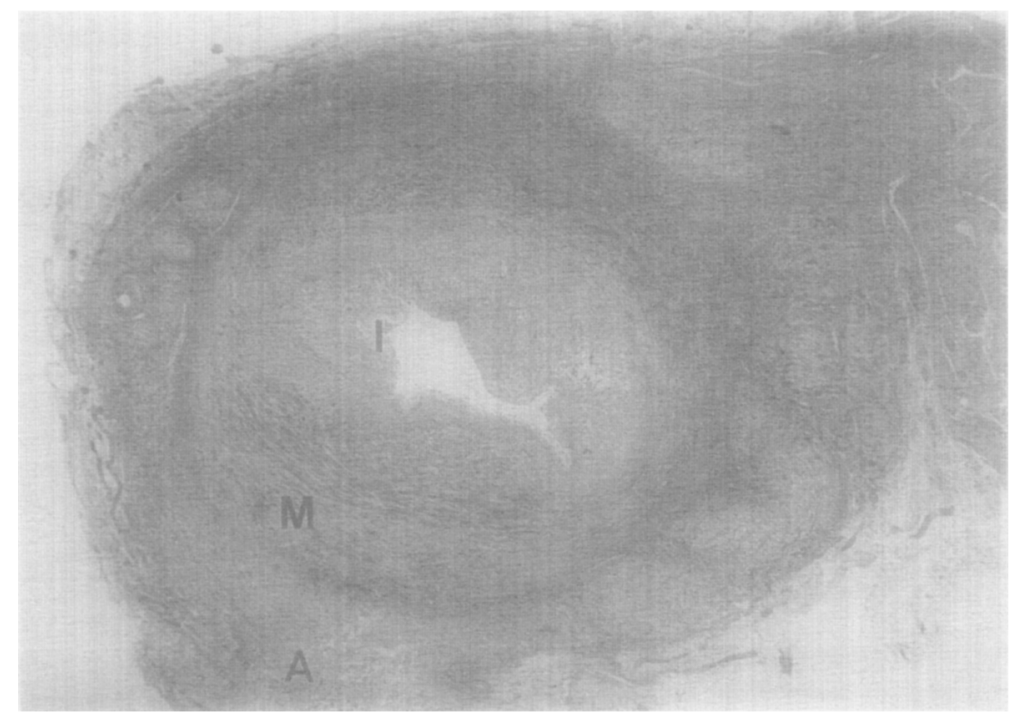

Fig. 5. Overview of a narrowed vein graft. The completely endothelialized graft shows both medial ( $M$ ) and intimal ( $I$ ) hyperplasia, consisting of smooth muscle cells within a collagenous matrix. $A$, Adventitia: (Goldner trichrome stain; original magnification $\times 10$.)

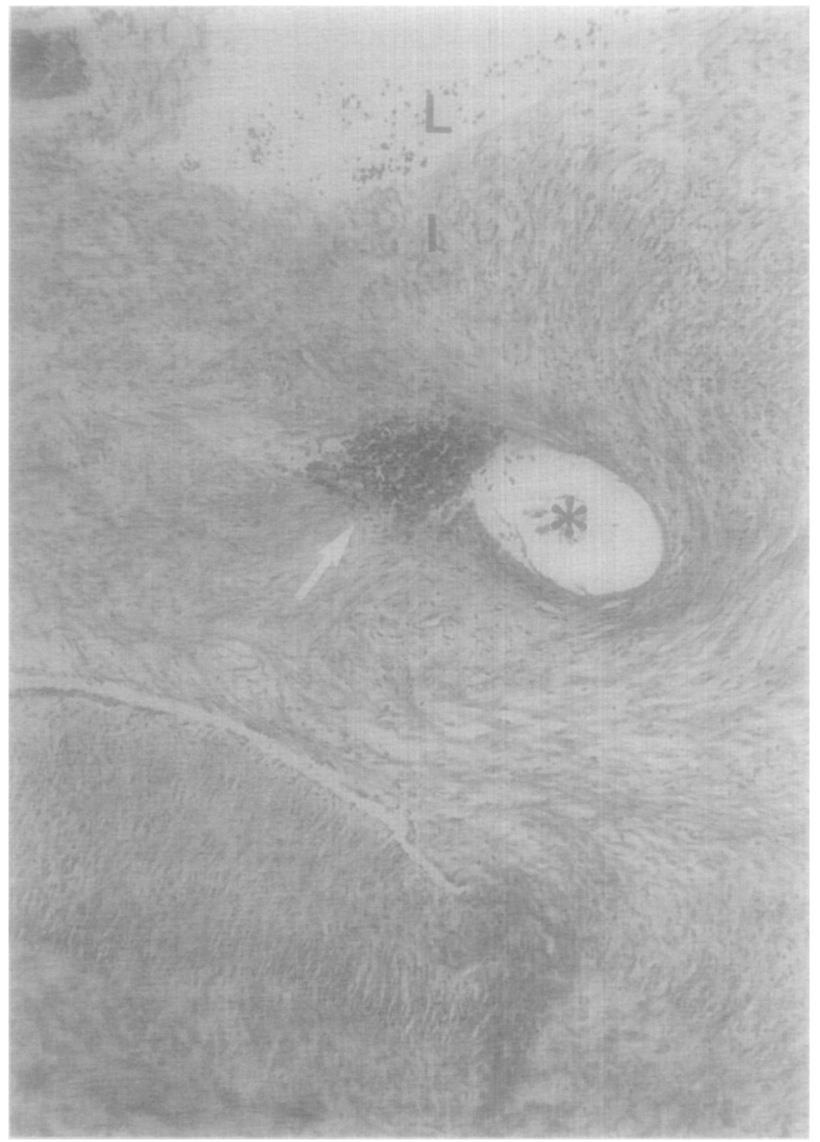

Fig. 6. Detail of a graft after stent implantation. Near the voids that remain after removal of the wires $\left(^{*}\right)$, thrombus remnants (arrow) are still conspicuously present 1 month after implantation of the prosthesis. $L$, Lumen; $I$, intina. (Goldner trichrome stain; original magnification $\times 40$.)
(Table I). In the group receiving multiple stents, however, only $17 \%$ proved to be patent ( $p<0.05$ vs all groups).

Quantitative angiographic analysis. In all grafts the minimal luminal diameter (MLD) was localized at an anastomotic site. The baseline data show (Fig. 4, A) that the mean MLDs of the intervention groups were smaller than those of the no intervention group, but not significantly different. Balloon dilatation, as well as the placement of single or multiple stents, resulted in a similar immediate improvement of the mean angiographic MLD $(0.6 \pm 0.3,0.8 \pm 0.3$, and $0.5 \pm 0.2$ $\mathrm{mm}$, respectively; Fig. 4, $B$ ). After 4 weeks of followup, no change was observed in the mean MLD of the group without intervention, although some changes in lumen diameter were observed (Fig. $4, B$ ). All intervention groups showed a significant deterioration of MLD $(p<0.05)$ when compared with the diameter after intervention, resulting in loss of the initial gain. Although the loss of mean MLD during follow-up tended to be smaller for the single stent group compared with the balloon group, this difference between the groups did not reach levels of statistical significance. The loss in MLD of the multiple stent group $(2.4 \pm 0.2 \mathrm{~mm})$, however, was significantly larger when compared with that of all other groups (Fig. $4, B ; p<0.05$ ) because of the high occlusion rate of $83 \%$. When considering only those grafts that remained patent throughout the study, we found that for both balloon angioplasty and single stenting there was no decrease in mean MLD throughout the follow-up period. Only multiple stenting was associ- 


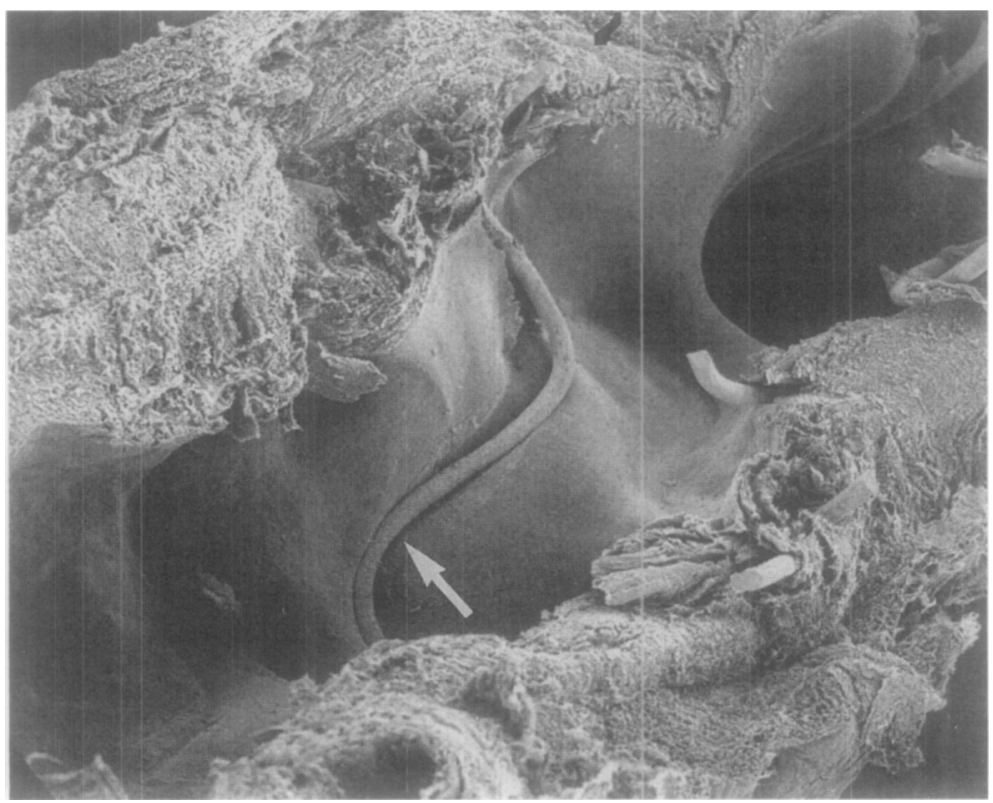

Fig. 7. Scanning electron microscopy of a vein graft 4 weeks after implantation of the stent. Note that not all wires have become embedded in the vessel wall (arrow).

ated with a net decrease in mean MLD (by $1.9 \pm 0.3$ $\mathrm{mm}$ ).

Histology of the vein graft. The gross morphology of the grafts was variable. Both tight stenoses at the anastomoses and aneurysmal dilatation of the body of the grafts were frequently observed. The adjacent carotid artery was usually normal. In all treated as well as untreated grafts, we observed both medial and neointimal thickening, which consisted of smooth muscle cells (confirmed with a positive staining for anti-smooth muscle cell-specific $\alpha$-actin at immunocytochemistry) in a collagenous matrix (Fig. 5). Most graft segments contained hemosiderin-filled macrophages and inflammatory infiltrates. At the anastomoses we observed inflammatory reactions surrounding the suture and the hemoclip. Macrophages were found containing crystalline inclusions, indicating that the inflammatory response was indeed directed to the 6.0 suture (Prolene, Ethicon, Inc., Somerville, N.J.). In the single stent treatment group, we observed that 4 weeks after stent implantation thrombus remnants surrounding the metal wires were conspicuously present (Fig. 6). The metal wires were not always embedded in the vessel wall (Fig. 7). Also, inflammatory infiltrates surrounding the stent wires were observed in the neointima, as well as an occasional multinucleate giant cell. The adjacent carotid arterial side of the anastomosis was less affected.

\section{DISCUSSION}

Porcine model of autologous saphenous vein grafting. The autologous saphenous vein is still the most com- mon conduit for aortocoronary bypass grafts in humans. The vein graft model used in this study (overdistended vena saphena minor interposed in the arteria carotis communis by two end-to-end anastomoses) ${ }^{13}$ shows extensive intimal hyperplasia that is histologically similar to early graft failure in humans (Fig. 8). In this model we compared the behavior of single or multiple balloon-expandable Wiktor stents with the results of balloon angioplasty alone or with the results of no intervention.

Acute effect of stenting of the 31-day-old vein graft. Scanning electron microscopy revealed that except for the visible damage directly underneath the wires, no apparent damage to the vessel wall was inflicted by the implantation procedure, as demonstrated by the microscopically normal endothelium. Because of the coil configuration of the stent, however, the luminal side was not smooth after the procedure (Fig. $3, A)$. The resulting flow disturbances might in turn induce thrombus deposition and persistent endothelial damage, which may both influence the process of intimal hyperplasia.

Angiography. From the angiograms the grafts were classified during the procedure qualitatively (by visual assessment) either as having only mild stenoses (later quantitatively analyzed as $32 \%$, range $23 \%$ to $60 \%$ ), in which case no further treatment was given, or as having severe stenoses $(48 \%$, range $19 \%$ to $70 \%$ ), in which case they were assigned to either balloon angioplasty, single stenting, or multiple stenting. Although some differences in angiographic MLD were observed between the intervention groups 
Fig. 8. Early graft failure in humans resembles graft failure in pigs, both showing medial and intimal hyperplasia and excessive extracellular matrix production. I Intima; $M$, media; $A$, adventitia $V$, valve. (Goldner trichrome stain; original magnification $\times 10$.)

(Fig. 4, A), these differences were not statistically significant. In these groups angiography was again performed directly after the intervention. Comparison with the no intervention group revealed that only in the case of single stenting was a similar MLD created (Fig. 4, $B$ ).

During the 4 weeks of follow-up, a significant deterioration occurred in the mean MLD of all treatment groups. It seems, however, from the angiographic data of the grafts that remained patent throughout the study (Table I and Fig. 4, $A$ and $B$ ) that for the single stent and balloon angioplasty groups there are only two possible results in the final outcome. Either the increase in MLD after intervention is maintained or treatment results in total occlusion. Single stenting, however, does seem able to better maintain the procedural increase in MLD than balloon angioplasty alone (Fig. 4, $B$ ).

Histology and immunocytochemistry. Human saphenous vein bypass grafts studied within 1 month after surgery reveal minimal to mild fibrointimal hyperplasia. Some of this narrowing may well be preexisting, since Thiene et al. ${ }^{16}$ reported that of 150 grossly "normal" veins, only 10 were totally free of microscopic phlebosclerosis. The porcine vein grafts from our study exhibited a more extensive fibrointimal hyperplasia. The high occlusion rate of $45 \%$ is likely to be the result of overdistention-induced injury and thrombosis superimposed on intimal hyperplasia, as indicated by hemosiderin deposits and neovascularization. Following stent implantation, plasma proteins, platelets, and leukocytes adhere to the metal wires. When compared with healthy, normal vessels, the thrombotic response to injury tends to be more pronounced in vessels with a previous history of disease such as intimal thickening, ${ }^{17}$ and might act in synergy with the stent.

From the histology of stented anastomotic sites, we observed that the intimal thickening was more pronounced in the grafts than in the adjacent "normal" carotid artery. Additionally, thrombus remnants that were still conspicuously present in the graft in close apposition to the stent wires were cleared in the carotid artery within the same period. This indicates that either the thrombotic response to this type of injury is indeed more pronounced, or that the organization of the thrombus is delayed or impaired in the graft. More likely is a combination of both, since the incomplete incorporation of the stent in the vessel wall is indicative of a slow-healing wound. In addition, histologic examination of stents in older human vein grafts revealed the persistence of thrombus remnants. ${ }^{12}$

Balloon angioplasty versus stenting with single or multiple endoprostheses. In this model of early saphenous vein graft stenosis, balloon angioplasty and single stents resulted in comparable short-term patency rates and mean MLD. Preliminary clinical results of placement of a self-expanding metal stent in older vein grafts suggest that this treatment has a more favorable clinical course when compared with that of balloon angioplasty. ${ }^{16}$ The implantation of multiple stents, however, yielded significantly more luminal narrowing at follow-up in our experiments. Therefore our results suggest that the implantation of multiple stents is not indicated in early bypass 
graft failure. Whether the same applies to late vein graft stenosis remains to be determined, but preliminary reports indicate that in humans, multiple stenting is indeed associated with an increased risk for restenosis. ${ }^{18}$

Limitations of the study. Several factors may limit the conclusions from this study: (1) The nonrandom distribution of grafts may have been an advantage for the "no intervention" group, because their initial diameter was larger than that of the others. The mean diameter of the grafts that remained patent throughout the study also indicate this to be an important parameter. Although some controversy still exists on the importance of the initial diameter, it was found that a small vessel diameter increased the risk of stent thrombosis, as did the use of small stent sizes. ${ }^{19}$ (2) Histologic analysis showed that at 2 months inflammatory infiltrates were still present in the untreated grafts and especially at the anastomotic sites. The relatively early interventions (only 1 month after grafting) while healing was still ongoing may have elicited a second more pronounced inflammatory process, which may have disturbed wound healing and increased intimal and medial hyperplasia or even promoted (secondary) thrombotic occlusion. Better results may be expected if the intervention is delayed until healing of the vessel wall is completed.

Conclusions. The present study shows that single stenting and balloon angioplasty seem able to maintain the increase in MLD during follow-up when patent grafts only are considered, and in the case of single stenting there is less variability. Overall, however, these techniques do not decrease or significantly improve patency (as assessed by angiography) when stents are placed early (within 31 days) after grafting. Multiple stenting of porcine saphenous vein carotid bypass grafts, however, results in decreased patency. Additional antithrombotic therapy might have yielded better results.

We thank Robert van Bremen for his technical assistance and indispensable help during the experiments.

\section{REFERENCES}

1. Grondin CM. Late results of coronary artery grafting: is there a flag on the field? J Thorac Cardiovasc Surg 1984;87:161-6.

2. Chesebro JH, Fuster V, Elevebaeck LR, Clements LR, Smith HC, Holmes DR, Bardsley WT, Pluth JR, Wallace RB, Puga FJ, Orszulak TA, Piehler JM, Danielson GK, Schaff HV, Frye RL. The effect of dipyridamole and aspirin on late vein graft patency after coronary bypass operations. N Engl J Med 1984;310:209-14.

3. Schaff HV, Orszulak TA, Gersh BJ, Piehler JM, Puga JM, Danielson GK, Pluth JR. The morbidity and mortality of re- operation for coronary artery disease and analysis of late $[13$ sults with use of actuarial estimate of event-free interval. $J$ Thorac Cardiovasc Surg 1983;85:508-15.

4. Foster ED, Fisher LD, Kaiser GC, Myers WO. Comparison of operative mortality and morbidity for initial and repeat con. onary artery bypass grafting: the Coronary Artery Surgery Study (CASS). Ann Thorac Surg 1984;38:563-70.

5. Lytle BW, Loop FD, Cosgrove DM, Taylor PC, Goormastic M. Gill CC, Golding LAR, Stewart RW. Fifteen hundred coronary reoperations. J Thorac Cardiovasc Surg 1987;93:847-59.

6. De Scheerder IK, Strauss BH, De Feyter PJ, Beatt KJ, Baur LHB, Wijns W, Heyndrix GR, Suryapranata $H$, van den Brand M, Buis B, Serruys PW, Morel MAM, Montauban van Swijndrecht E. Stenting of venous bypass grafts: a new treatment modality for patients who are poor candidates for reintervention. AM HEART J 1992;123:1046-54.

7. Plokker HWT, Meester BH, Serruys PW. The Dutch experience in percutaneous transluminal angioplasty of narrowed saphenous veins used for aortocoronary arterial hypass. Am .] Cardiol 1991;67:361-6.

8. Urban P, Sigwart U, Golf S, Kaufmann U, Sadeghi H, Kappenberger L. Intravascular stenting for stenosis of aortocoronary venous bypass grafts. J Am Coll Cardiol 1989;13:108591.

9. Serruys PW, Strauss BH, Beatt KJ, Bertrand ME, Puel J, Rickards AF, Meier B, Goy JJ, Vogt P, Kappenberger L, Sigwart U. Angiographic follow-up after placement of a self-expanding coronary stent. N Engl J Med 1991;324:13-7.

10. Serruys PW, Strauss BH, van Beusekom HMM, van der Giessen WJ. Stenting of coronary arteries: has a modern Pandora's box been opened? J Am Coll Cardiol 1991;17:143b-54b.

11. Anderson PG, Bajaj RK, Baxley WA, Roubin GS. Vascular pathology of balloon-expandable flexible coil stents in humans. J Am Coll Cardiol 1992;19:372-81.

12. Van Beusekom HMM, van der Giessen WJ, van Suylen RJ, Bos E, Bosman FT, Serruys PW. Histology after stenting of human saphenous vein bypass grafts: observations from surgically excised grafts 3 to 320 days after stent implantation. $J$ Am Coll Cardiol 1993;21:45-54.

13. Angelini GD, Bryan AJ, Williams HMJ, Morgan R, Newby AC. Distention promotes platelet and leucocyte adhesion and reduces short-term patency in pig arteriovenous bypass grafts. J Thorac Cardiovasc Surg 1990;99:433-9.

14. Van der Giessen WJ, Serruys PW, van Beusekom HMM, van Woerkens LJ, van Loon H, Soei LK, Strauss BH, Beatt KJ, Verdouw PD. Coronary stenting with a new, radiopaque, balloon-expandable endoprosthesis in pigs. Circulation 1991; 83:1788-98.

15. Reiber JHC, Serruys PW, Kooijman CJ, Wijns W, Slager CJ, Gerbrands JJ, Schuurbiers JCH, den Boer A, Hugenholtz PG. Assessment of short-, medium-, and long-term variations in arterial dimensions from computer-assisted cineangiograms. Circulation 1985;71:280-8.

16. Thiene G, Miazzi P, Valsecchi M, Valente M, Bortolotti U, Casarotto D, Gallucci V. Histological survey of the saphenous vein before its use as autologous aortocoronary bypass graft. Thorax 1980;35:519-22.

17. Groves HM, Kinlough-Rathbone RL, Richardson M, Jorgensen L, Moore S, Mustard JF. Thrombin generation and fibrin formation following injury to rabbit neointima: studies of vessel wall reactivity and platelet survival. Lab Invest 1982; 46:605-12.

18. Fajadet J, Doucet S, Caillard J, Cassagneau B, Robert G, Marco J. Predictors of restenosis after Palmaz-Schatz implantation [Abstract]. Circulation 1992;86:I-531.

19. Agarwal SK, Hearn JA, Liu MW, Cannon AD, Bilodeau L, Iyer SS, Baxley WA, Dean LS, Roubin GS. Stent thrombosis and ischemic complications following coronary artery stenting [Abstract]. Circulation 1992;86:I-113. 